\title{
Prediction of the High Voltage Insulators Service Life Based on the Effective Values of Leakage Currents
}

\author{
Breido Iosef ${ }^{1}$, Ivanov Valeriy ${ }^{2}$ \\ ${ }^{1,2}$ Department of Industrial Ptocesses Automation, Karaganda Technical University, Kazakhstan
}

\begin{tabular}{l}
\hline \hline Article Info \\
\hline Article history: \\
Received Feb 16, 2021 \\
Revised Apr 27, 2021 \\
Accepted May 11, 2021 \\
\hline
\end{tabular}

\section{Keywords:}

high voltage insulators insulation state monitoring leakage current insulator service life

\begin{abstract}
The insulation condition of overhead lines is one of the main factors affecting reliability of overhead power transmission lines. It is known that the process of insulation lapping or rupture is mainly affected by environmental conditions and the degree of pollution of the insulators surface. This paper substantiates the possibility of using the leakage current values of insulators for monitoring the state of insulation and predicting its resource. The results of experimental studies of leakage currents of high-voltage insulators depending on their service life are given, on the basis of which forecasting the possible resource of insulators is carried out. The results obtained can be used to develop more effective diagnostics for detecting insulator failures at an early stage to take appropriate measures to coordinate the insulation.
\end{abstract}

Copyright $(2021$ Institute of Advanced Engineering and Science. All rights reserved.

\section{Corresponding Author:}

Ivanov Valeriy,

Department of ${ }^{1}$ Industrial Ptocesses Automation,

Karaganda Technical University,

56 N. Nazarbaev av., Karaganda 100012, Kazakhstan.

Email: v.ivanov@kstu.kz

\section{INTRODUCTION}

Insulators for overhead power transmission lines are one of the most important elements of highvoltage lines. The performance of the entire power supply system depends on their state. Ensuring high reliability of insulation is one of the most important tasks of the power industry. In this regard, the issue of the reliable assessment of the insulation service life is of particular importance. The problem of diagnosing the state of insulation is already several decades old but this does not make it less urgent.

Damageability of insulation of high-voltage overhead power transmission lines (OHPL) is about $30 \%$ of the total number of violations in their work. The main causes of insulation damage are the effect of climatic impacts, atmospheric and switching overvoltage, aging of insulation, inconsistency with natural and climatic conditions of operation, etc. [1, 2, 3].

All the currently existing methods of diagnostics of insulation are based on the results of periodic checks and are divided into two types: contact and non-contact. Some methods can be used directly on power transmission lines without disconnecting supply voltage, such as: measuring the voltage distribution on a string of insulators, thermal imaging methods and methods based on registration of ultraviolet radiation. Other methods can be used only in the laboratory conditions and require disconnection of supply voltage in the line, which leads to increasing economic losses: measuring insulation resistance, dielectric loss tangent, insulation capacitance and overvoltage testing [4-7].

Thus, the existing methods solve the problems of the current periodic monitoring of the state of insulators in order to determine the critical level of the permissible insulation resistance. They are ineffective, take a long time to troubleshoot and do not allow real-time monitoring of the insulation condition under operating voltage. 
The analysis of the published materials shows that present day works are mainly dealing with assessing the current state and predicting the probability of insulation flashover [8-25]. As practice shows, after the overlap, the insulation continues to function normally. Thus, insulation flashover is not a criterion for assessing its service life and cannot be used to predict its service life.

The paper proposes possible options of solving this problem on the basis of experimental studies.

\section{STATEMENT OF THE PROBLEM}

The main parameter characterizing the insulation dielectric strength is the leakage current value. The insulator can be represented in the form of the equivalent circuit shown in Figure 1. The insulator is characterized by the following parameters: the value of the insulator material resistance $R_{v}$ and the values of surface resistances $R_{p}$ and capacitance $C_{p}$, which characterize the properties of the surface layer of pollution [4].

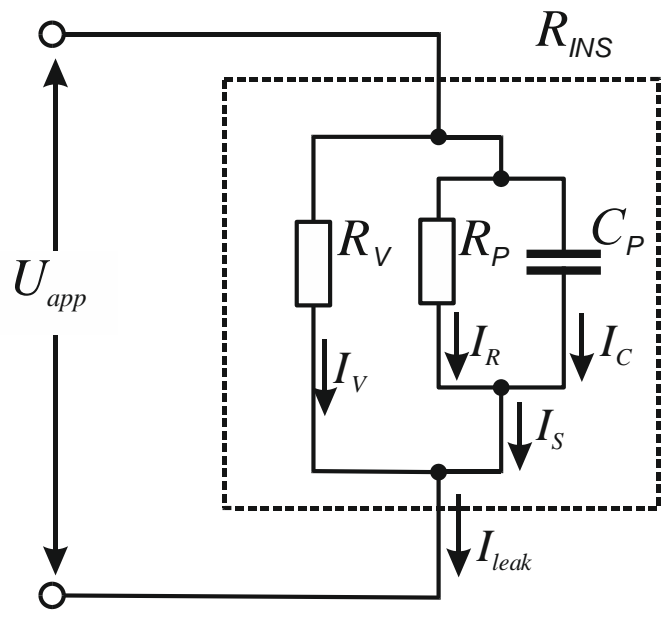

$R_{I N S}$ - insulation resistance; $I_{\text {leak }}$ - leakage current; $U_{\text {app }}$ - voltage applied to the insulation in the course of measuring and testing; $R_{p}, C_{p}$ - resistance and capacitance of the pollution surface layer; $I_{V}-$ throughconduction current; $I_{S}$ - surface leakage current; $I_{R}$ - active surface current; $I_{C}$ - capacitive surface current.

Figure 1. Insulator equivalent circuit

The insulation state is determined by leakage current, which is the sum of the through-conduction current $I_{V}$ (volume current) and surface current $I_{S}$ determined by the total insulation resistance conventionally shown in Fig. 1 in the form of resistance $R_{I N S}$. Moreover, the conduction current $I_{V}$ determines the degree of the insulator material (dielectric degradation), and the surface current $I_{S}$ the degree of the insulator pollution.

$$
I_{\text {leak }}=I_{V}+I_{S}=\frac{U_{a p p}}{R_{V}}+\left(\frac{1}{R_{p}}+j \omega C_{p}\right)
$$

The total leakage current of insulators consists of the volume component that determines the quality of the insulator material, and the surface component that determines the amount of insulation pollution. Increasing the leakage current value characterizes deterioration of the insulator dielectric strength and leads to significant increasing the probability of its surface flashover.

The information obtained in the analysis of leakage current parameters, such as: the number of pulses, peak values, the effective value, the phase angle, charge accumulation, harmonic decomposition, is used to assess the level of pollution, the degree of dielectric aging, as well as to predict the insulation flashover voltage [8-19].

So, in $[8,9,10]$, the authors propose to use changing the amplitude and effective values of leakage current as a criterion for identifying critical conditions in dielectrics; in [11 - 14], it is proposed to use the harmonic analysis of leakage current to control the pollution level. Work [15] is dealing with the use of the partial discharges parameters; in [16,17], the authors use a change in the effective value and phase angle of the leakage current to determine the insulators condition.

Thus, measuring of the leakage current parameters is mainly used to determine the magnitude of pollution and insulators flashover voltage, but the possibility of using the leakage current parameters to predict the insulators service life and to determine the degree of degradation (aging) of the dielectric material is not 
considered [8 - 25]. Therefore, it is of interest to use the leakage current parameters to determine the degree of degradation (aging) of the dielectric material and to predict the service life of insulators.

At the same time, surface pollution of insulators also affects leakage current. This conclusion can be made based on the analysis of published studies, from which it follows that:

(1) In the course of operation, due to the combination of mechanical impacts and ultraviolet radiation, there takes place slight erosion of the insulator surface, which increases its irregularities and leads to the accumulation of dirt on it;

(2) When moistened, the conducting medium is formed on the surface of the insulator, which changes the capacitive character of leakage current to resistive;

(3) Uneven distribution and moisture content of pollutants cause uneven distribution of the voltage gradient over the surface, and in places with a high gradient voltage, partial surface discharges occur, which increases leakage current;

(4) The flow of partial discharges and leakage current is accompanied by local heating and contributes to the aging of the insulator material;

(5) As the surface irregularities increase, the accumulation of pollutants increases and the aging of the insulator accelerates.

Thus, surface pollution also contributes to increase leakage current over time. Therefore, it is proposed to use the effective measured values of leakage current as a criterion for predicting the service life of insulators and determining the degree of degradation (aging) of the dielectric material, which take into account both the aging of the dielectric and the effect of surface pollution arising in the course of operation.

\section{EXPERIMENTAL STUDIES OF HIGH-VOLTAGE INSULATION STATE ON THE BENCH}

To determine the possibility of assessing the high-voltage insulators state and predicting their service life based on the values of leakage current $\left(I_{\text {leak }}\right)$, a test bench diagram for measuring the insulation quality has been developed (Figure 2).

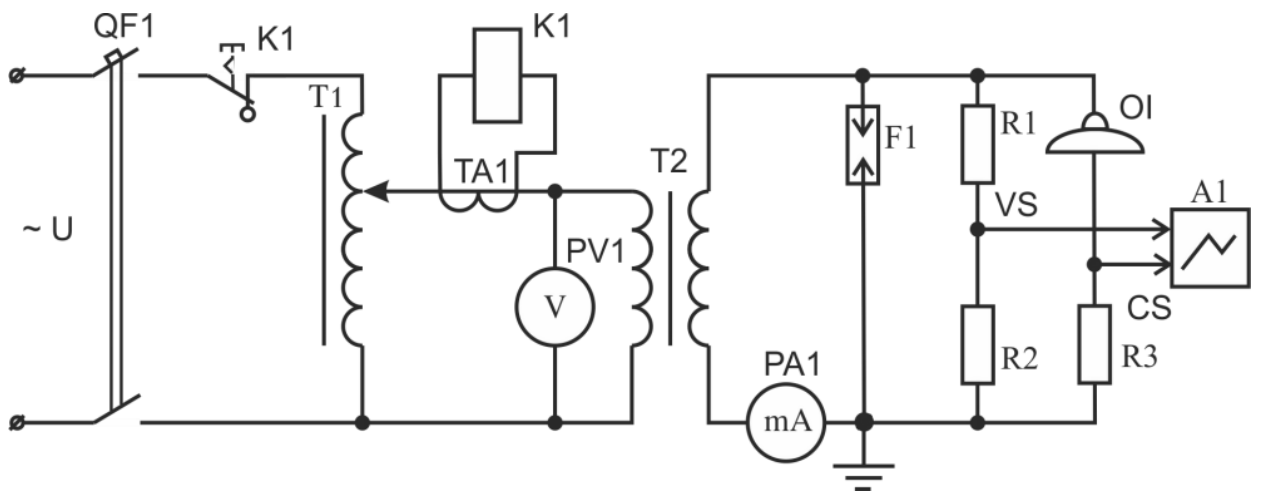

QF1 - circuit breaker, T1 - single-phase autotransformer, T2 - test transformer; TA1 - current transformer;

K1 - electromagnetic current relay; VS - voltage sensor; R1, R2 - voltage divider resistors; OI - object of inquiry (insulator); CS - current sensor based on the resistor R3; F1 - spark gap; A1 - oscilloscope; PV1, PA1 - electrical measuring instruments.

Figure 2. Test bench circuit for measuring the insulators parameters

To measure Ileak, high voltage is applied to the OI (insulator) from the output of the test transformer T2. Voltage regulation is performed on the low side of the test transformer by means of a single-phase laboratory autotransformer T1 with the voltage regulation limit from 0 to $250 \mathrm{~V}$. Applied voltage is measured using a voltage sensor (VS) based on a resistive voltage divider R1; R2, and measuring of the Ileak value of the insulator (OI) is performed using a current sensor (CS) based on the current shunt R3, the signals from which are fed to the oscilloscope A1. For visual control, the leakage current value is measured with a PA1 milliammeter. To ensure protection of transformers from the flow of currents exceeding the nominal values, current protection is installed on the basis of the K1 current relay connected through the TA1 current transformer into the secondary circuit of the autotransformer.

The measurements have been performed indoor under the following conditions: the ambient temperature is $21^{\circ} \mathrm{C}$ and humidity is $43 \%$. Before testing, the insulator surfaces are cleaned by washing with isopropyl alcohol, and rinsing with distilled water in order to remove any trace of dirt and grease. For each insulator, leakage current is measured in dry conditions under AC voltage. 
The measurements have been performed in the following way: by gradually increasing voltage and recording its values with the use of a voltmeter, as well as the corresponding $\underline{I}_{\text {leak }}$ value. Measuring $\underline{I}_{\text {leak }}$ has been performed 60 seconds after voltage was applied to the insulator. Leakage current has been measured on 30 new, 26 used in operation within 10 years and 16 insulators used within 30 years, type PS120B. The technical characteristics of the insulators are shown in Table 1 and Figure 3.

Table 1. Technical parameters of insulators

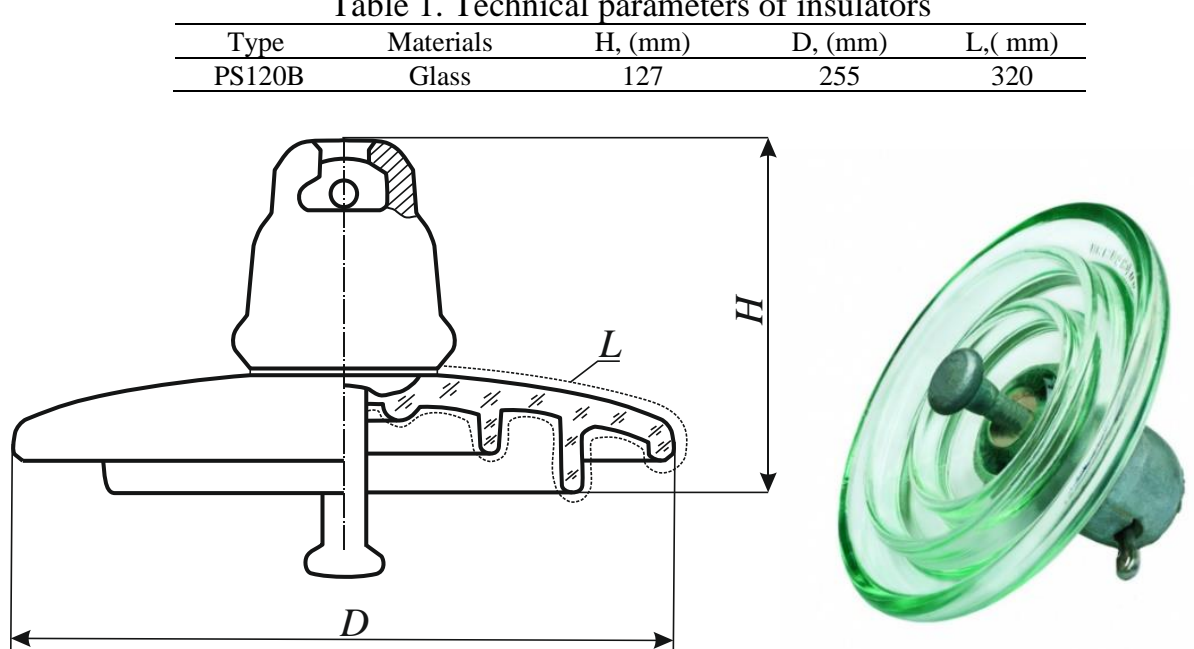

Figure 3. Profile and appearance of the PS120B type insulator

\section{DISCUSSION OF THE RESULTS OBTAINED}

As previously mentioned, the leakage current is the sum of two components: the surface current $I_{S}$, which depends on the degree of the insulator surface contamination, and the volume current $I_{V}$, which determines the degree of material dielectric aging. Since clean dry insulators were used to measure the leakage current, it can be said that the value of the leakage current is determined only by the volume component of the leakage current, which depends on the service life and operating conditions of the insulators.

The graphs of the insulators leakage currents measured values studied as a function of the applied voltage. According to the data obtained, the leakage current graphs for new and preexisting insulators as a function of the applied voltage shown in Figure 4 are plotted.

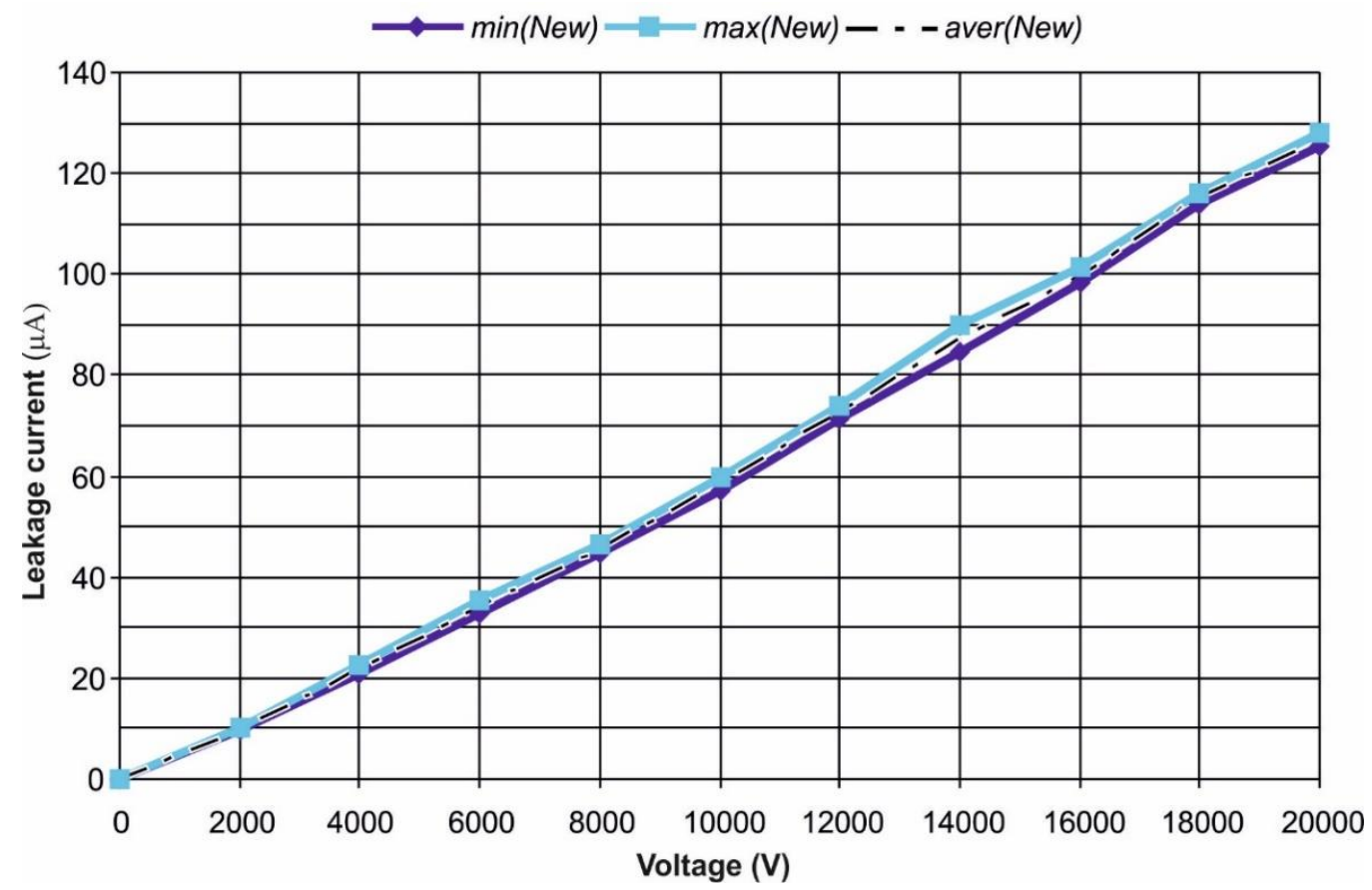

Figure 4. Insulator leakage currents dependence on applied voltage for new insulators 
In the graphs there is shown the range of variation of leakage current values from the minimum $(\min (\mathrm{New}))$ to the maximum $(\max (\mathrm{New}))$, as well as the average $(\operatorname{aver}(\mathrm{New}))$ values of the leakage current of new insulators. The graphs show that for new insulators there is practically no variation in the leakage current from the average value. This suggests that the insulation state of new, not previously used, insulators is almost completely identical.

In Figure 5 the graphs there are shown the range of variation of leakage current values from the minimum $(\min ($ Old10 $))$ to the maximum $(\max ($ Old10 $))$, as well as the average (aver $($ Old10)) values for the used within 10 years insulators.

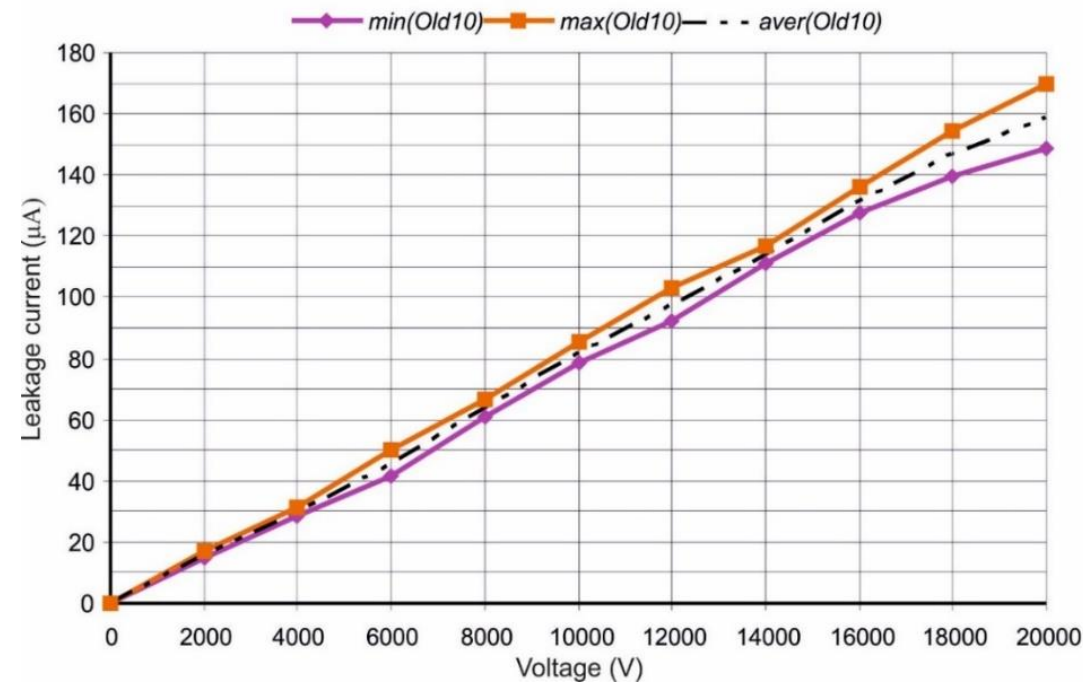

Figure 5. Insulator leakage currents dependence on applied voltage for used within 10 years insulators

At the same time, for used insulators this spread is from $\pm 5 \%$ to $\pm 23 \%$. Moreover, with an increase in the applied voltage, the value of the deviation of the leakage current from the average value increases. This is due to different operating conditions and, accordingly, different degrees of insulation degradation.

The range of variation from the minimum ( $\min (30 O l d))$ to the maximum (max $(30 O l d)$, as well as the average (aver $(\mathrm{New})$ ) values of the leakage current of used within 30 years insulators shown in Figure 6.

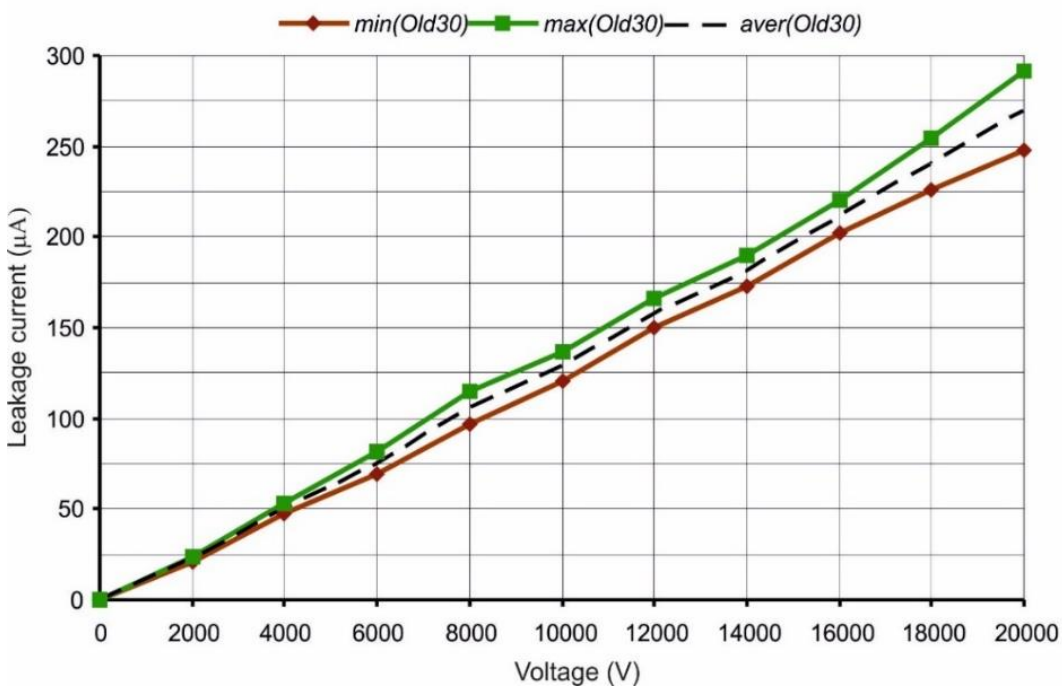

Figure 6. Insulator leakage currents dependence on applied voltage for used within 30 years insulators

The experiment results on the leakage current average values produced with various testing voltages and insulators service life are indicated in a form of graphics in Figure 7. As indicated, at each position of the operating life has been an increase in leakage current if the applied voltage is increasing. As indicated, the leakage current is increases if service life increasing. 


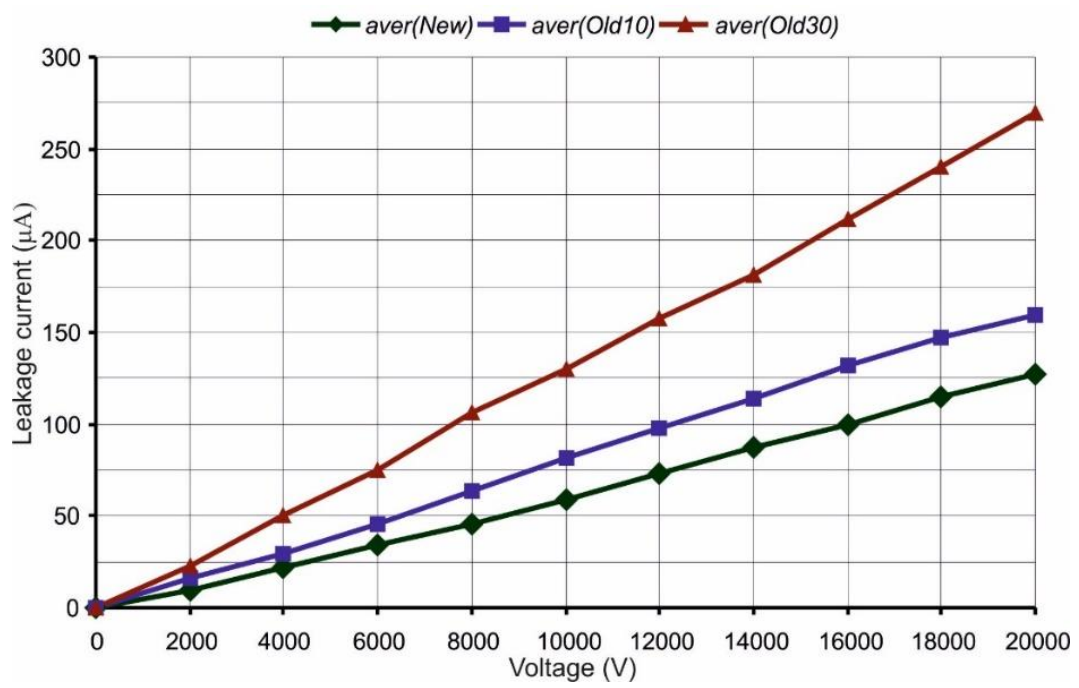

Figure 7. Leakage current as a function of the applied voltage for various insulators service life

Analysis of the results shows that the values of leakage current of insulators depends on their service life. So, for example, the leakage current value of insulators that were in these operating conditions for 10 years is approximately 1.25 times greater than that of new ones, and the leakage current of insulators that have been used for 30 years is more than twice the leakage current of new insulators (comparison of data aver(New), aver(Old10) and aver(Old30), respectively).

Thus, the conclusion about the possibility of using the leakage current as a criterion for determining the degree of degradation of the insulator material is confirmed. When this current reaches the maximum permissible value, the operation of the insulators must be stopped.

\section{METHODS OF PREDICTING THE INSULATORS RESOURCE}

Based on the experimental data obtained, a method is proposed for predicting the service of insulators consisting in the following.

Knowing initial leakage current $I_{\text {leak init }}$ of the new insulator and setting maximum permissible leakage current $I_{\text {leak perm }}$ at which its operation should be terminated, let's build a straight line of the theoretical service life $\mathrm{T}_{\mathrm{SL} \text { theor }}$ of the insulator (Figure 8, line 1).

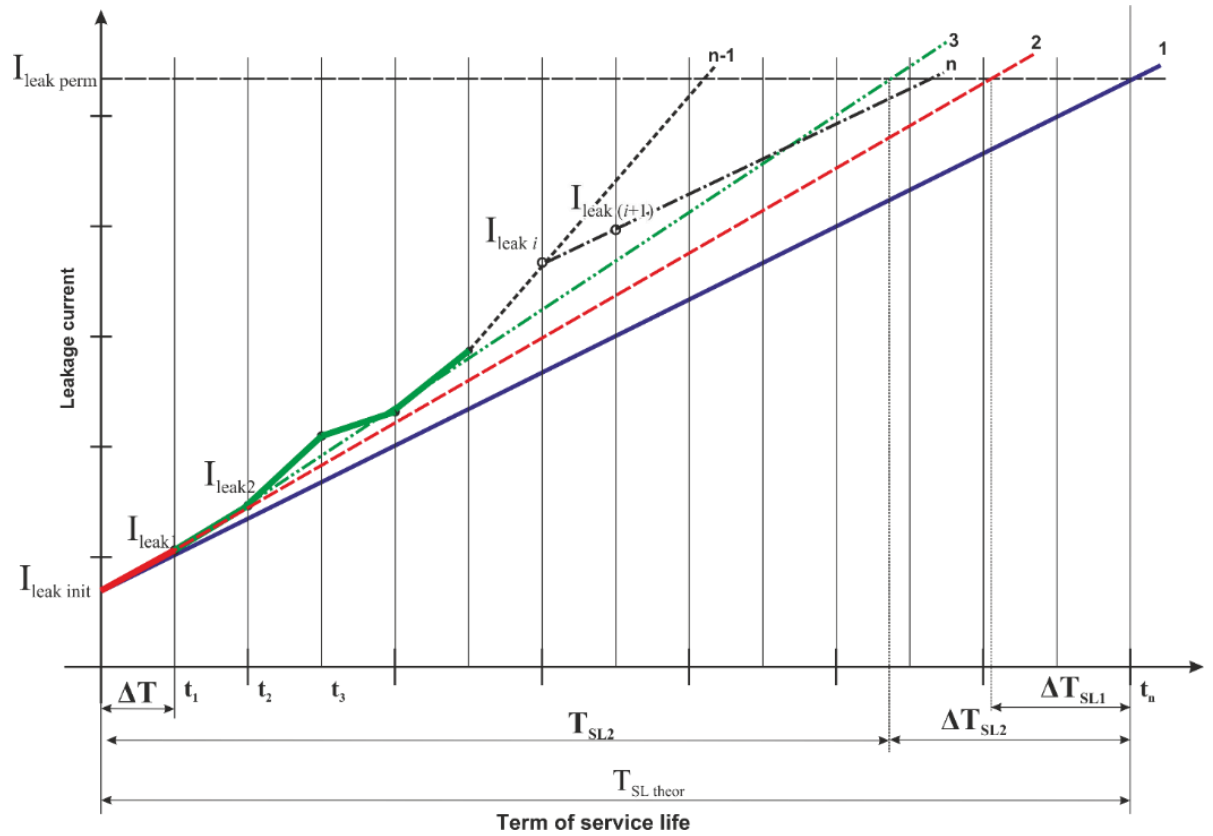

Figure 8. Predicting the insulator service life 
The forecast line of the insulator service will be constructed using a piecewise linear approximation.

The line of the insulator service life forecast is built with the use of piece-wise linear approximation by dividing the duration of the insulator operation into intervals of $\Delta \mathrm{T}$. In the general case the line equation has the form:

$$
A x+B y+C=0 \text {. }
$$

Let us divide the terms of equation (2) by $\mathrm{B}$ and write it down with relative to $\mathrm{y}$. As a result, we obtain the equation of a straight line along a point and a slope ratio:

$$
y=-\frac{A}{B} x-\frac{C}{B}=k x+b .
$$

The value of the $b$ variable is obtained equal to the value of the leakage current in the previous interval $b=I_{\text {leak }(i-1)}$. For $t=0$ the value of the $b=I_{\text {leak init }}$ variable is obtained.

By measuring actual leakage current of the insulator and setting the time interval $\Delta \mathrm{T}$ of the leakage current averaging, we obtain the value of leakage current as a function of the operating time:

$$
I_{\text {leak }}=f\left(t_{1}, t_{2}, \ldots, t_{n}\right) \text {. }
$$

The value of the interval $\Delta \mathrm{T}$ is determined by the operating conditions of the insulators and the required speed of response to changes in the state of the insulator dielectric strength. For surface leakage current of an insulator, this interval can be from a day to a week, since this current characterizes the amount of the insulator pollution and is a relatively fast process. At the same time, volume leakage current that characterizes the degree of the insulator dielectric degradation, is a long process and the averaging interval can be from one to several months, especially at the initial stage of the insulator operation, when the value of volume leakage current is much lower than surface current and can be ignored. Later on, with increasing the operating time, the value of volume leakage current increases.

The value of the slope ratio $k$ is determined by the rate of changing the state of the insulation (its drive) and is found by the expression:

$$
k=\frac{I_{\text {leak }(i)}-I_{\text {leak }(i) \text { aver }}}{t_{i}-t_{(i-1)}},
$$

where $I_{\text {leak }(i) \text { aver }}$ is the average value of leakage current from the moment of operation start.

Thus, we obtain the value of leakage current for the operating time $t_{l}$. Using expression (5), we find the slope ratio and build a possible line for predicting the service life of insulators (Figure 8 , line 2 ). In this case, we obtain a possible change in the service life $\Delta \mathrm{T}_{\mathrm{SL} 1}$, corresponding to changing the state of the insulators under these operating conditions.

Similarly, we determine the value of leakage current $I_{\text {leak } 2} \ldots I_{\text {leak (i) }}$ and obtain the possible lines for predicting the service life of the insulator at different values of insulation condition (Figure 8 , lines $3 \ldots n$ ). Thus, with accumulation of the data (the number of time intervals of averaging) of the actual leakage current value $I_{\text {leak }(i)}$, the value of the slope ratio k makes it possible to take into account changing the state of insulation during operation and the forecast accuracy increases.

The graph shows that the expected service life of the insulators differ by the value $\Delta \mathrm{T}_{\mathrm{SL}}$, characteristic for the conditions in which the studied insulators have been operated. Certainly, when the natural and climatic conditions of the operation area change, the predicted service life of the insulators will be different.

In this case, if in the previous interval $\Delta \mathrm{T}$ of monitoring, surface pollution, for example, due to a dust storm, increased, then leakage current will also increase, and the residual resource will decrease. If in the current monitoring interval rainfall washes away a part of the pollution, then leakage current will decrease, and the residual resource will increase. Consequently, the residual resource will be constantly adjusted.

The described technique was published by the authors in [26]. On the basis of this method, there was issued the RK patent [27]. To implement the proposed method, a comprehensive system of protection and diagnostics of overhead line elements has been proposed and developed, which collects and transmits the information of the current state of insulation over GSM networks in real time from leakage current sensors of strings of overhead line insulators placed on supports [28, 29].

Increasing leakage current also leads to increasing the power losses. The amount of power losses $\mathrm{P}_{\text {leak }}$ can be defined as:

$$
P_{\text {leak }}=U_{\text {app }} \cdot I_{\text {leak }} \text {. }
$$

The power losses obtained for different service life of insulators depending on voltage applied are presented in Figure 9. 


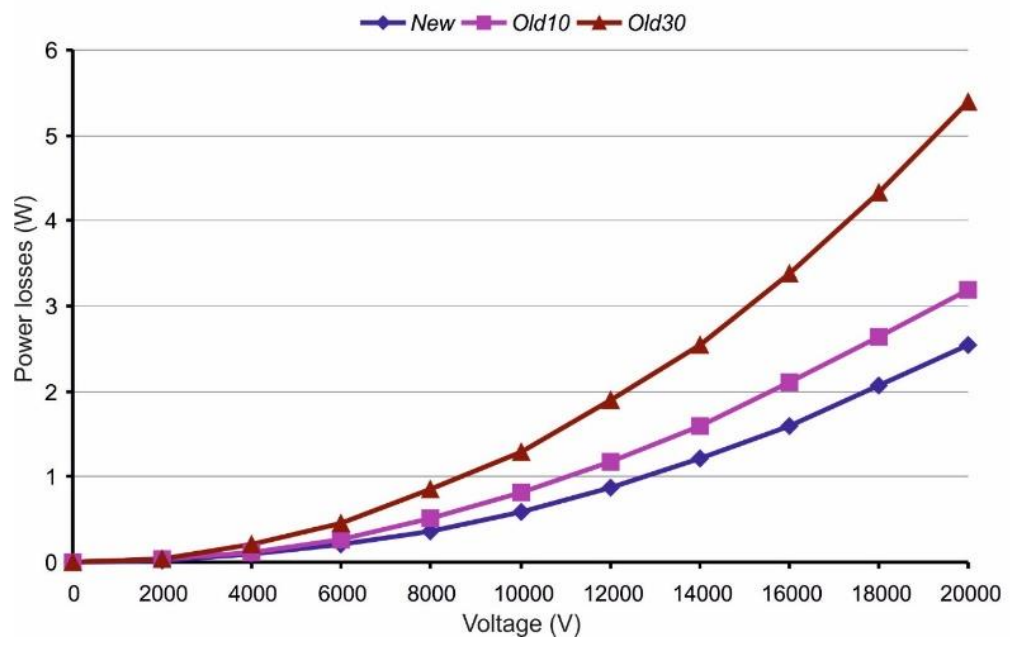

Figure 9. Power losses as a function of applied testing voltage of a glass insulator for three different insulators service life

Figure 9 shows that changing the value of applied voltage significantly affects the value of the active power losses of the insulator. Losses depend on the insulator resistance and are proportional to the leakage current square. The loss is manifested as heat on the insulator material, which leads to thermal aging of the insulator material. As voltage applied to the insulation increases, the aging rate increases and the service life of the insulators decreases accordingly.

\section{STUDYING FORECAST METHODOLOGY UNDER OPERATION CONDITIONS}

For technical implementation of the methodology, it was necessary to provide effective monitoring of leakage currents of high-voltage insulators under operating conditions directly from the OHPL supports.

The technique has been refined during testing of an experimental model of the system of remote monitoring leakage currents of high-voltage insulators that was developed with participation of the authors. To measure leakage currents, a sensor with telemetric information transmission has been used [30,31]. Conduction volume and surface current are generated in the sensor.

Experimental studies of leakage currents have been performed under operating conditions. To measure leakage currents, a new and clean insulator has been placed in an external environment where it was exposed to external atmospheric effects. The values of leakage currents from the output of the current sensor have been transmitted via the GSM network to a computer, where the research results were stored and processed.

The sensor as a part of the system has been tested within 2 months (62 days). During the tests the recording of leakage currents of the insulator have been made with discreteness at least once an hour. Then, these data have been averaged, and the average value of leakage current per day has been determined. An example of averaged daily leakage current values is shown in Figure 10.

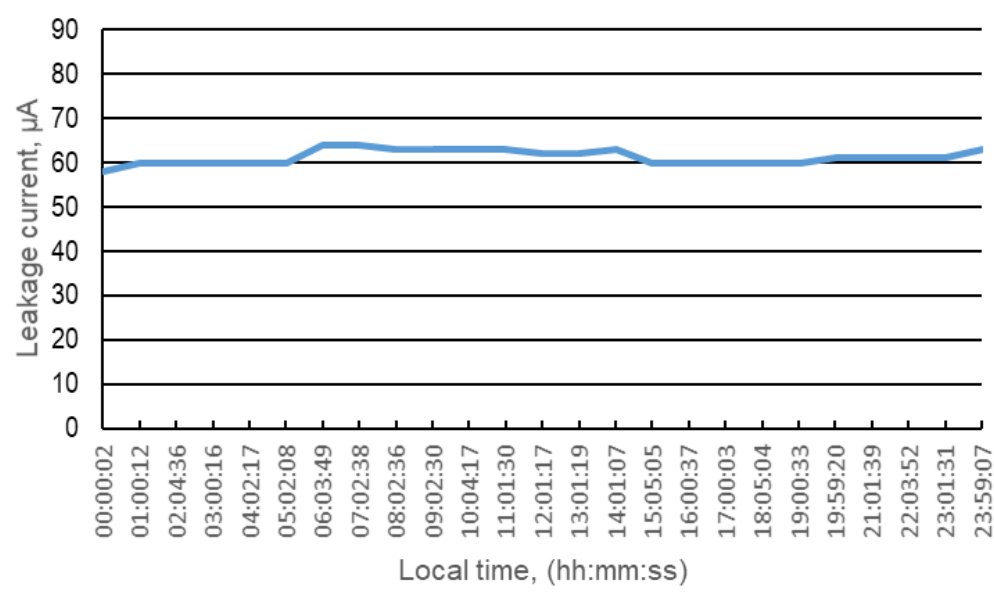

Figure 10. Averaged daily leakage current values of the PS120B insulator 
The graphs of the obtained values for leakage current within the first and second months of testing are shown in Figure 11. To assess the effect of external factors on leakage current, average daily values of temperature and humidity taken from [32] are plotted on the same graphs.

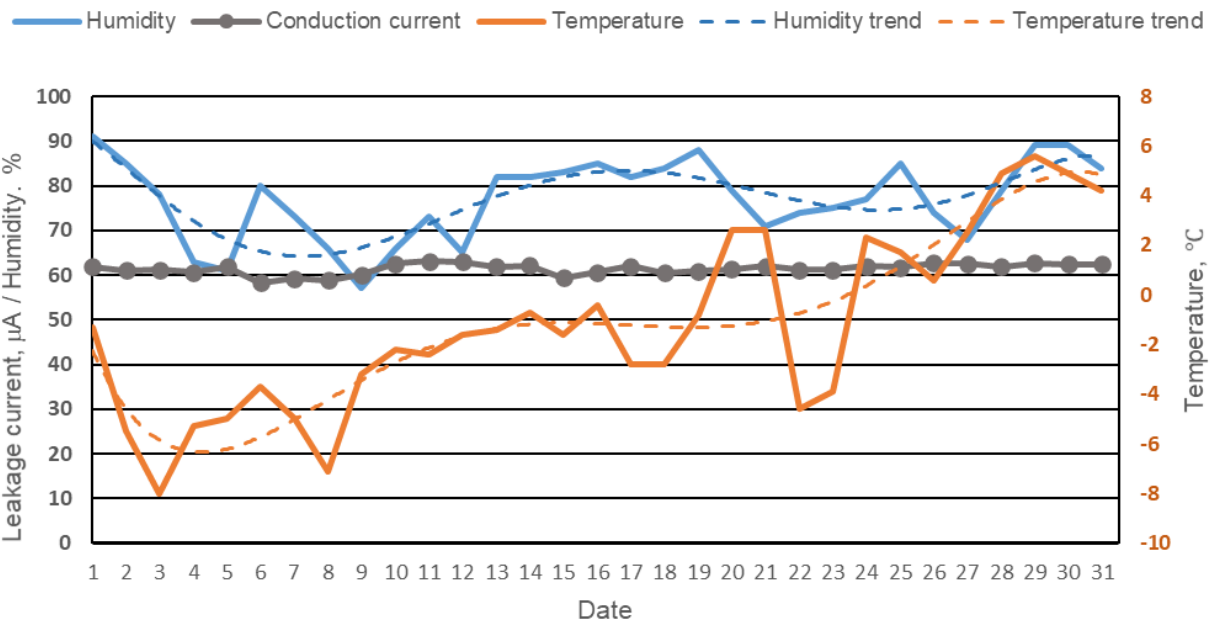

a) conduction current

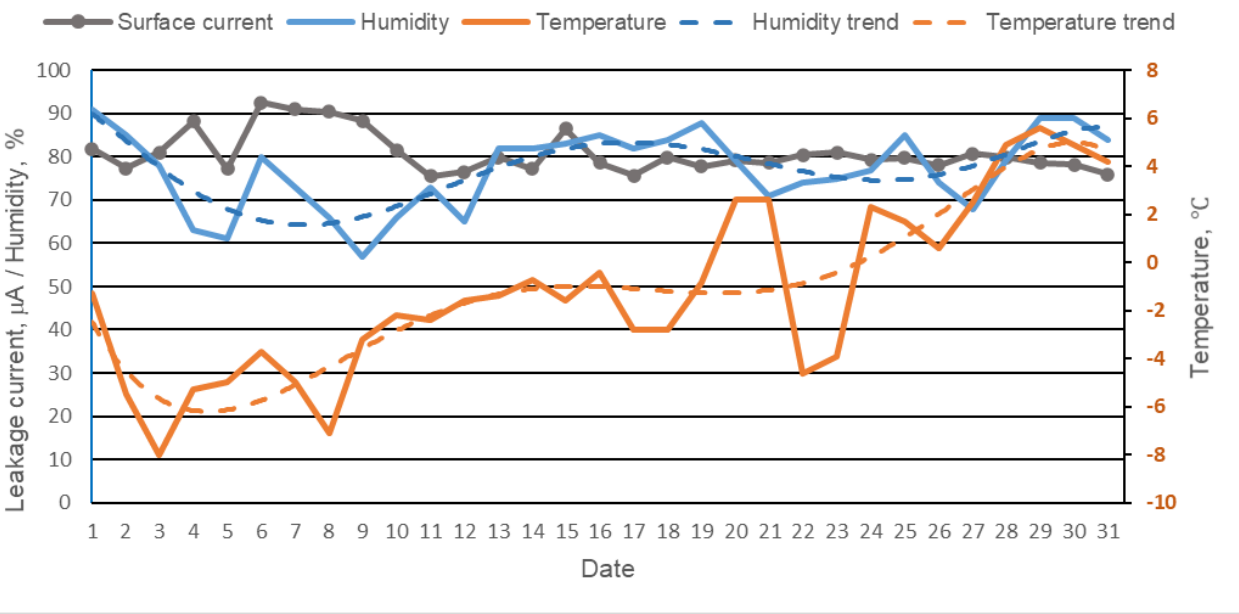

b) surface current

Figure 11 - Insulator leakage current for the first month

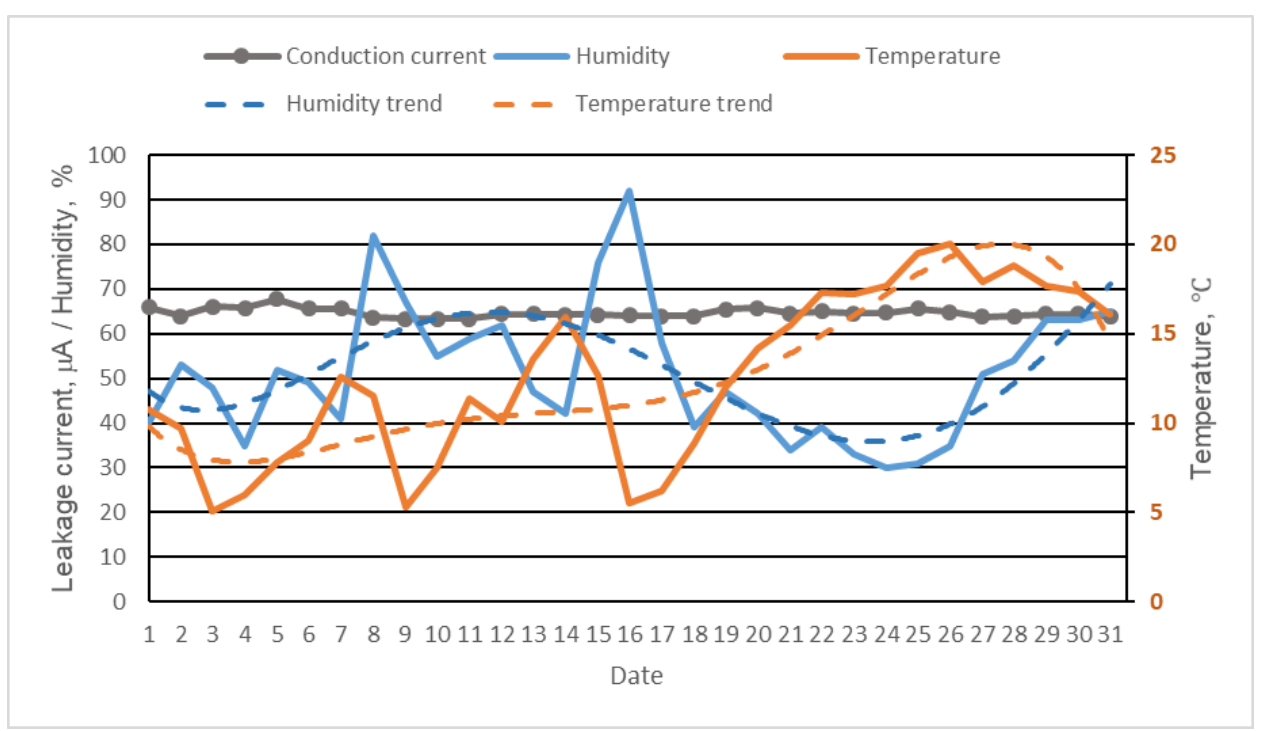

a) conduction current 


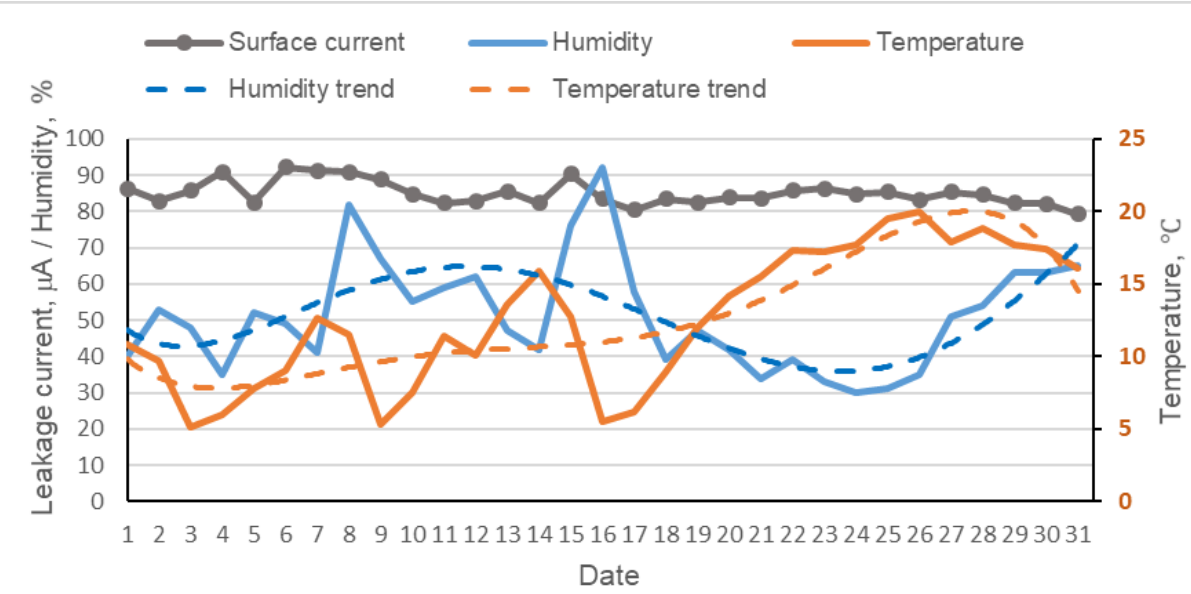

b) Surface current

Figure 12. - Insulator leakage current for the second month

The analysis of the data obtained allows concluding that external factors (humidity and temperature) do not practically affect the value of the conduction current values of the insulator. Temperature changes have a little effect on the surface current values, while humidity has a significant effect. The values of the correlation coefficient for temperature and humidity for conduction current were $\mathrm{K}_{\text {corr } \mathrm{T}}=-0.11, \mathrm{~K}_{\text {corr } \mathrm{H}}=0.26$. For surface current, the values of the corresponding coefficients were: $K_{\text {corr } \mathrm{T}}=-0.20, \mathrm{~K}_{\text {corr H }}=-0.68$.

\section{PREDICTING INSULATOR LEAKAGE CURRENTS BASED ON EXPERIMENTAL RESULTS}

Based on the experimental data of leakage currents obtained within 62 days in accordance with the proposed method, presetting the time interval of 1 week, we obtain 8 full intervals. To test the technique operability, we will perform forecasting the possible values of the leakage current of insulators for different numbers of time intervals. Table 2 shows the results of measuring the actual and predicted values of leakage current of the insulator performed with the use of the method described above for 3 time intervals using Microsoft Excel.

Table 2. Leakage current values for 3 time intervals

\begin{tabular}{ccccc}
\hline Time interval & $\begin{array}{c}\text { Actual leakage current } \\
\text { value, } \mu \mathrm{A}\end{array}$ & $\begin{array}{c}\text { Forecast } \\
(\mu \mathrm{A})\end{array}$ & $\begin{array}{c}\text { Lower boundary of the } \\
\text { confidence interval, }(\mu \mathrm{A})\end{array}$ & $\begin{array}{c}\text { Upper boundary of the } \\
\text { confidence interval, }(\mu \mathrm{A})\end{array}$ \\
\hline 1 & 87.4 & & & \\
2 & 85.33 & & & \\
3 & 96.21 & 96.208571 & 96.21 & 96.21 \\
4 & 84.54 & 98.941866 & 91.47 & 106.41 \\
\hline
\end{tabular}

Figure 13 shows the graph of insulator leakage currents built according to Table 2.

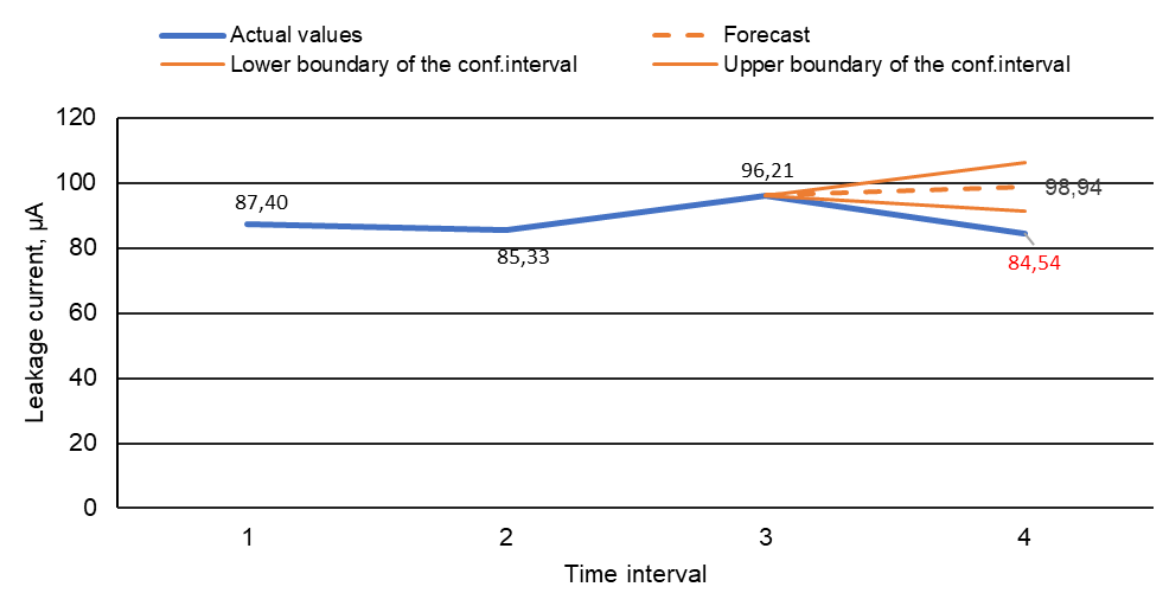

Figure 13. Predicting the insulator leakage current values with 3 time intervals 
It is seen from the presented graph that for a given number of time intervals, the actual value of leakage current does not fall within the calculated confidence interval. Since the number of the obtained actual values of the leakage current is limited to 8 , in order to be able to compare the actual and calculated values, we will perform forecasting the values of the leakage current for 6 time intervals. Table 3 presents the data of actual and forecasted possible leakage current values for 6 time intervals.

Table 3. Leakage current values for 6 time intervals

\begin{tabular}{ccccc}
\hline Time interval & $\begin{array}{c}\text { Actual leakage current } \\
\text { value, }(\mu \mathrm{A})\end{array}$ & $\begin{array}{c}\text { Forecast } \\
(\mu \mathrm{A})\end{array}$ & $\begin{array}{c}\text { Lower boundary of the } \\
\text { confidence interval, }(\mu \mathrm{A})\end{array}$ & $\begin{array}{c}\text { Upper boundary of the } \\
\text { confidence interval, }(\mu \mathrm{A})\end{array}$ \\
\hline 1 & 87.4 & & & \\
2 & 85.33 & & & \\
3 & 96.21 & & & \\
4 & 84.54 & & & \\
5 & 91.38 & 92.777143 & 92.78 & 92.78 \\
6 & 92.78 & 96.267977 & 89.64 & 102.90 \\
7 & 95.31 & 91.51553 & 84.83 & 98.20 \\
8 & 91.63 & & & \\
\hline
\end{tabular}

Figure 14 shows the graph of insulator leakage currents built according to Table 3.

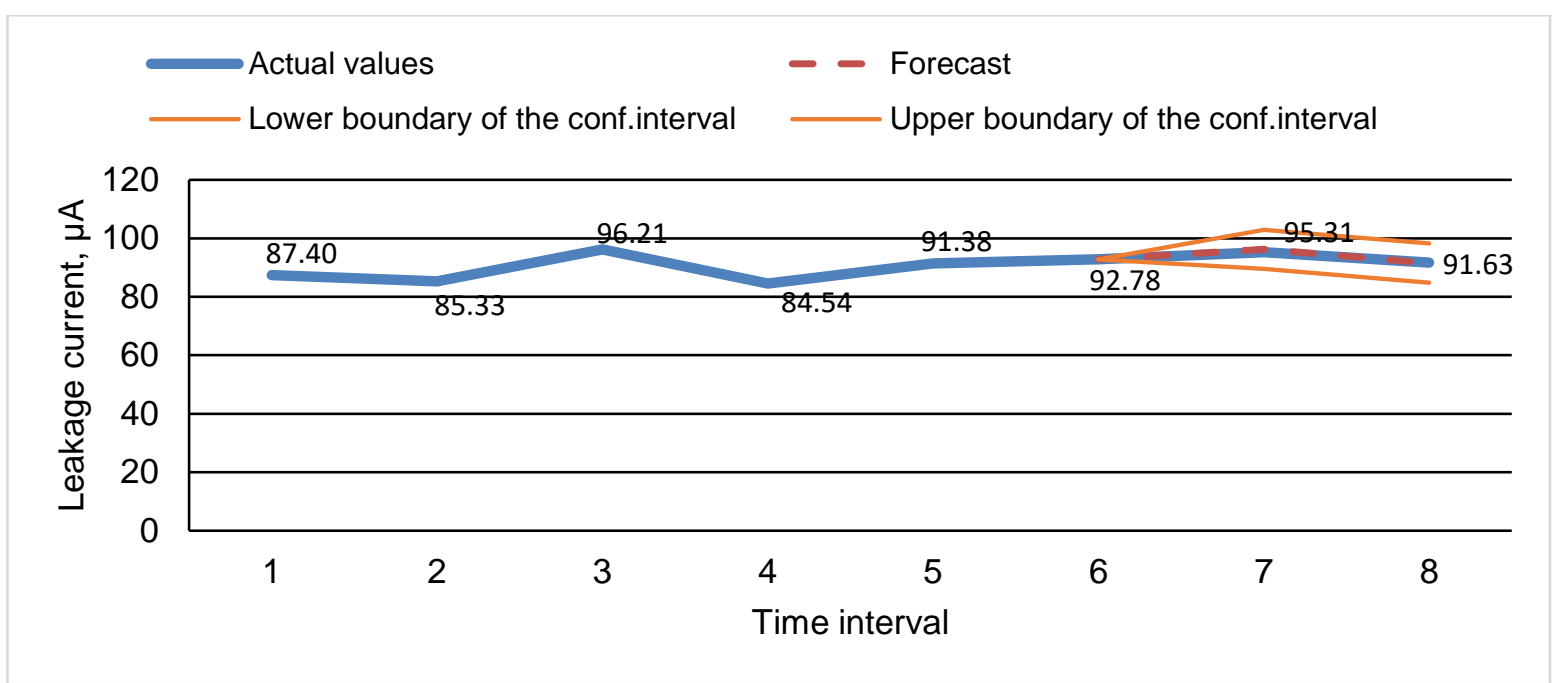

Figure 14. Predicting the leakage current values with 6 time intervals

From the Figures presented follows that as the actual values of leakage current accumulate (the number of time intervals increases), the forecast accuracy increases and, starting from some minimum amount, the predicted values of leakage current do not go beyond the confidence interval with the accepted reliability $\mathrm{p}=0.95$.

Thus, it is obvious that the number of time intervals affects the accuracy of forecasting the state of insulation according to the proposed method, and to increase the accuracy of the forecast, it is necessary to increase the number of time intervals.

It is not advisable to make a forecast for a larger number of intervals due to the limited amount of available data. With accumulation of the data of the leakage currents values obtained within subsequent time intervals, the forecast accuracy will increase, which is confirmed by the already available experimental data based on the results of two-month tests. The conclusions made confirm the possibility of using the proposed iterative method based on a constant correction of the forecast based on the results of accumulated experimental data.

\section{CONCLUSION}

It has been established that insulators that have been in operation for 10 years have leakage current of about 1.25 times higher than that of new ones, and insulators that have been used for 30 years it is more than twice leakage current of new insulators. Based on the results of the analysis carried out, theoretical and experimental studies, a method is proposed for determining the residual life of high-voltage insulators of overhead high-voltage power lines. It is proposed to use the effective average value of leakage current of highvoltage insulators as a criterion for assessing the residual life. 
The technique is based on the remote monitoring of leakage currents of high-voltage insulators located on supports by periodically adjusting the residual life. Within 62 days, experimental studies of the developed technique were carried out in real operating conditions. The remote monitoring of the overhead line insulation state was performed with the use of an experimental model of the telemetric system for monitoring leakage currents of high-voltage insulators.

\section{ACKNOWLEDGEMENT}

The materials of the work used the results of theoretical and experimental studies obtained within the framework of the grant on the topic No. IRN AR08856344 "Development of a complex for remote monitoring of the state of structural elements of high-voltage overhead power lines during operation based on intelligent noise-immune telemetry systems."

\section{REFERENCES}

[1] Kaverina R., Kogan F., Yakovlev L. "Increase of reliability of overhead lines 35-750 kV. The complex of works and proposals", M., Electrical News Journal. vol. 47, no. 5, 2007.

[2] Yakovlev L., Kaverina R., Dubinich L.,"The complex of works and proposals to improve the reliability of a high voltage line at the design and operation stages"/Power lines: design, construction, operating experience and scientific and technological progress, Novosibirsk, 2008, pp. 28-50,

[3] Kashevarov S.G., "Damage to power lines and review of new technical and organizational solutions for their restriction", Current State and Development Prospects of Technical Sciences: Collection of articles of the International Scientific and Practical Conference (May 23, 2015. Ufa), Ufa: MTSIA Omega Sainz Ed., 2015, pp.5863.

[4] Kuffel J., Zaengl W. S., Kuffel E. High Voltage Engineering Fundamentals and electrophysics, Dolgoprudny: Publishing House "Intellect", 2011.

[5] Arbuzov R.S., Ovsyannikov A.G., "Diagnostic methods for glass and polymer insulation". Power lines-2004: Operating experience and scientific-technical Progress, Thesis at the 1st intern. scientific-practical conf., Ed. by T. Chernov, Novosibirsk, 2004, pp. 57-65.

[6] Arbuzov R.S., Ovsyannikov A.G., Modern methods of diagnostics of overhead power lines, Novosibirsk: Nauka, 2009.

[7] Standard operating instructions for overhead power lines of 35 - $800 \mathrm{kV}, \mathrm{RD} 34.20 .504-94$ (approved by RAO "UES of Russia" on September 19, 1994), M.: ENAS Scientific Center, 2017.

[8] Shihab S., Melik V., Zhou L., et al. "Online pollution leakage current monitoring system," Proceedings of IEEE Properties and Application of Dielectric Materials, 3-8 July 1994, pp. 538-541.

[9] Werneck M. M., Santos D. M., Barros Allil et al, "Detection and Monitoring of Leakage Currents in Power Transmission Insulators," in IEEE Sensors Journal, vol. 15, no. 3, pp. 1338-1346, March 2015.

[10] Banik A., Dalai S., Biswendu Ch. "Condition Monitoring of Overhead line Insulator By measuring Surface Leakage Current" 2014 Annual IEEE India Conference (INDICON).

[11] Suda, "Study on the Frequency Characteristics of Leakage Current Waveforms of Artificially Polluted" $12 t$ Suspension Insulators by the Clean Fog Method", International Symposium on High Voltage Engineering, London, UK, 1999.

[12] Li J., Caixin S., Sima W., et al.: 'Contamination level prediction of insulators based on the characteristics of leakage current', IEEE Trans. Power Deliv., 2010, 25, (1), pp. $417-424$

[13] Palangar M. F., Mirzaie M. "Detection of Critical Conditions in Ceramic Insulators Based on Harmonic Analysis of Leakage Current" Electric Power Components and Systems, 00(00): 2016, pp. 1-11.

[14] Terrab H., El-Hag A., Bayadi A., "Characterization of leakage current on the surface of porcelain insulator under contaminated conditions" Electric Power and Energy Conversion Systems (EPECS), 2015 4th International Conference on, Sharjah, 2015, pp. 1-4.

[15] Salustiano R. et al., "Development of new methodology for insulators inspections on aerial distribution lines based on partial discharge detection tools," 2014 ICHVE International Conference on High Voltage Engineering and Application, Poznan, 2014, pp. 1-4.

[16] Palangar M. F., Mirzaie M. "Detecting of unnormal conditions of polluted insulators based on analysis phase angle of leakage current," Electrical Power Distribution Networks Conference (EPDC), 2015 20th Conference on, Zahedan, 2015, pp. 7-15.

[17] S. Chandrasekar, C. Kalaivanan, A.Cavallini and G. C. Montanan, "Investigations on Leakage Current and Phase Angle Characteristics of Porcelain and Polymeric Insulator", IEEE Transactions on Dielectrics and Electrical Insulation Vol. 16, No. 2, pp 574-583; 2009

[18] Merhalev S.D., Solomonik E.A., Insulation of lines and substations in areas with a polluted atmosphere, M.: Energia, 1973.

[19] Voskresensky V.F., Electrical insulation in areas with a polluted atmosphere, M.: Energy, 1971.

[20] Amin S., Amin. M., "Natural Aging of Sir Insulators in Pakistan," International Conference on Emerging Technologies, pp. 114-117, 2009.

[21] R. Sundararajan, A. Mohammed, N. Chaipanit, "In-service Aging and Degradation of $345 \mathrm{kV}$ EPDM Transmission Line Insulators in a Coastal Environment", IEEE Trans.Dielectr. Electr. Insul., vol. 11, pp. 348-361, 2004. 
[22] A.H. El-Hag, S. Jayaram \& E.A. Cherney "Fundamental and Low Frequency Harmonic Components of Leakage Current as a Diagnostic Tool to Study Aging of RTV and HTV Silicone Rubber in Salt-Fog" IEEE Transaction on Dielectrics and Electrical Insulation, Vol. 10, No. 1, February 2003, pp. 128-136.

[23] Z. Yang et al."Study on the Influence Rules of Soluble Contaminants on Flashover Voltage of Disc Suspension Insulators", IEEE Transactions on Dielectrics and Electrical Insulation Vol. 23, No. 6; December 2016, pp. 35233530 .

[24] Li, J.Y.; Sima, W.X.; Sun, C.X.; Sebo, S.A. Use of leakage currents of insulators to determine the stage characteristics of the flashover process and contamination level prediction. IEEE Transactions on Dielectrics and Electrical Insulation. 2010, 17, pp. 490-501.

[25] M. A. Douar, A. Mekhaldi, and M. C. Bouzidi, "Flashover process and frequency analysis of the leakage current on insulator model under nonuniform pollution conditions," IEEE Transactions on Dielectrics and Electrical Insulation, vol. 17, no. 4, pp. 1284-1297, 2010.

[26] Ivanov V.A., Breido I.V., Celebrovskiy U.V. "Monitoring the state and forecasting the insulation resource of highvoltage overhead power transmission lines", University Proceedings. Karaganda: KSTU. 2020, vol. 1(78). pp. 139143.

[27] I.V. Breido, V.A. Ivanov, et al) "Method and system of contactless and remote control of electric strength of chains of insulators of overhead high-voltage power lines"; RK patent No. 34012 Registered in the State Register of Inventions of the Republic of Kazakhstan on 11.13.2019.

[28] Breido I., Ivanov V., Kaverin V. "Telemetric Monitoring Insulation Condition of High Voltage Overhead Power Lines", Annals of DAAAM and Proceedings of 29th International DAAAM Symposium, 2018, pp. 319-328.

[29] Breido I., et al. "System of protection and diagnostics of structural elements of support of high-voltage power lines", Annals of DAAAM and Proceedings of 28th DAAAM International Symposium on Intelligent Manufacturing and Automation, , 2017, pp. 322-330.

[30] Breido I., Ivanov V., Kaverin V., Voytkevich S., Levin I., "Distributed system of protection and diagnostics of support structural elements of high-voltage power line", EAI Endorsed Transactions on Energy Web 4(13) e5, pp.1-7, 2017.

[31] V.A. Ivanov, I.V. Breido, Monitoring system for condition and predicting service life of insulators; RK Patent, 4601, September 05, 2019.

[32] Weather archive in Karaganda, https://rp5.kz/, November 21, 2019.

\section{BIOGRAPHY OF AUTHORS}

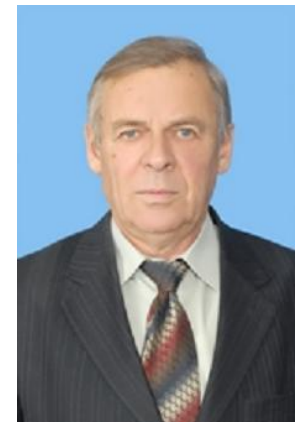

Breido Iosif (Prof), was born 03/21/1947 in Kyrgyzstan. In 1971 graduated from the Leningrad Electrotechnical Institute. V.I. Ulyanov (Lenin). Doctor of Technical Sciences of the Russian Federation (1997); Doctor of Technical Sciences of the Republic of Kazakhstan (1998); Professor (1999); Academician of the International Academy of Informatization (2000); Academician of the National Academy of Natural Sciences of the Republic of Kazakhstan (2009), Academician of the St. Petersburg Branch of the Engineering Academy of the Russian Federation (2017). Since 1988 to present he is working in KarTU, head of the department of industrial processes automation. His research interests are in the field of high voltage engineering, semiconductor electric drives, electrical equipment and automation systems, including processing and transmission systems of technological information for enterprises of the mining and smelting complex.

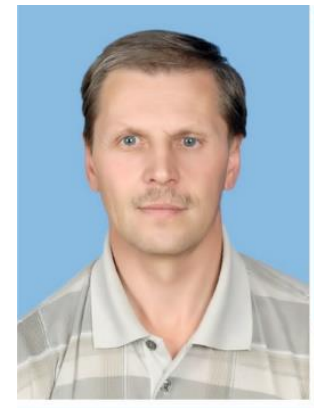

Ivanov Valeriy was born in Karaganda, Kazakhstan in 1961. In 1987 graduated from the Karaganda Technical University. MEng degree of Automation and Control, Karaganda Technical University, Kazakhstan in 2017. He is currently a senior researcher at Industrial processes automation department in KarTU. His research interests are in the field of high voltage engineering, semiconductor electric drives, electrical equipment and automation systems, including processing and transmission systems of technological information for enterprises of the mining and smelting complex. 